\title{
The Shared Space Phenomenon as a Tool for Rediscovering Mixed-Use Street
}

\section{Mgr. Anton OSTAKH}

Tutor: doc. Ing. arch. Irena Fialová; Ústav urbanismu, Fakulta architektury, České vysoké učení technické v Praze, Česká republika E-mail address: antonostx@gmail.com

\begin{abstract}
Strengthening the place quality and the balance between different users of the traditional central or local main street with mixed functions is the most topical issue for all modern developed cities, where car traffic and transport infrastructure dominate over a wide group of other transportation modes and land uses. Traffic hierarchization and segregation principles, in addition to the division of responsibility areas in streets between different professions, created two different, incompatible worlds - the highway and the public place. Nowadays, we can create a good highway for cars and perfect places for people individually, but when we try to combine them, the worst public space appears. It prevents the existence of mixed use streets (in both theory and legislation) and it still weakens their place quality in real life. The need to find a more suitable approach to calm traffic on the main, multifunctional streets in the Czech Republic is emphasized by the growth of the global phenomenon of shared space theory.
\end{abstract}

KEYWORDS: shared space; street design; mixed-use street; segregation; integration; risk compensation 


\section{Introduction}

The dominance of traffic and transport infrastructure over other users and activities in public spaces, where the exclusion of vehicles is neither desirable nor possible, is still a sensitive issue in many cities around the world, including the Czech Republic. In order to accommodate mechanized transport and, at the same time, reduce its negative impact on residences within cities, the transport road hierarchy was developed in the 1960s. But it ultimately disrupted the traditional city structure and the balance of mixed use streets - that is, places where the balance of transport (of all kinds) and residence of people is an essential part of urban life. To pose a solution for such places, so-called "home zones" of Dutch origin were created. Woonerf stands for residential streets, while winkelerf presented commercial ones. Despite having great success in achieving the set goals, they significantly limited car traffic (up to $300 \mathrm{cars} / \mathrm{h}$ ) and speed (up to $5 \mathrm{~km} / \mathrm{h}$ ), which made them suitable only for local roads outside the city center without transit traffic. It also had high implementation costs for the traffic-calming infrastructure and did not meet the requirements of blind, partially sighted, and deaf people. The need to find a more cost-effective approach for other localities has stimulated the performance of experiments in two basic directions in the Netherlands:

1. Using individual calming elements of traffic engineering in a wider area of the city - Zone 30;

2. Using psychological influence of the surrounding context on the behavior of the traffic participant - Shared space ${ }^{\mathrm{i}}$

\section{What is a mixed-use street, why do we need it, and why was it lost?}

A mixed-use street is the traditional high street, where a mix of retail, business, and public service is intermingled with residential dwellings, either above them or nearby.

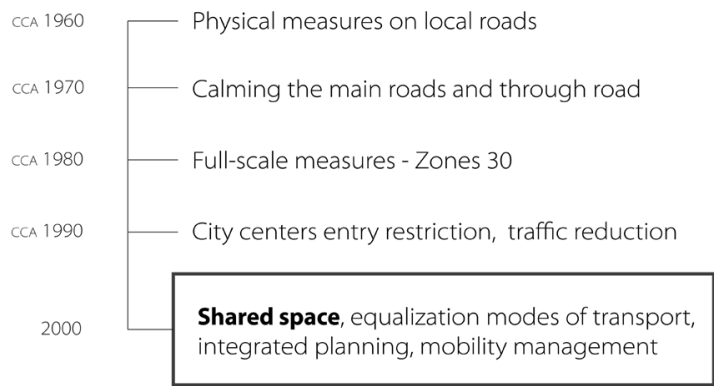

Fig. 1. Traffic calming historical evolution (Source: CDV, TP218). 


\section{LINK:}

Through movement by:

- Private cars, vans, goods vehicles

- Public transport

- Cycles

- Pedestrians

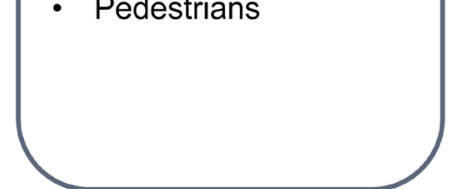

\section{PLACE:}

- People standing, sitting, sightseeing, shopping, trading

- Public performances, parades, demonstrations, etc.

- Parking (including cycle parking)

- Loading / servicing

Fig. 2. Link and Place activities (Source: UCL, London)

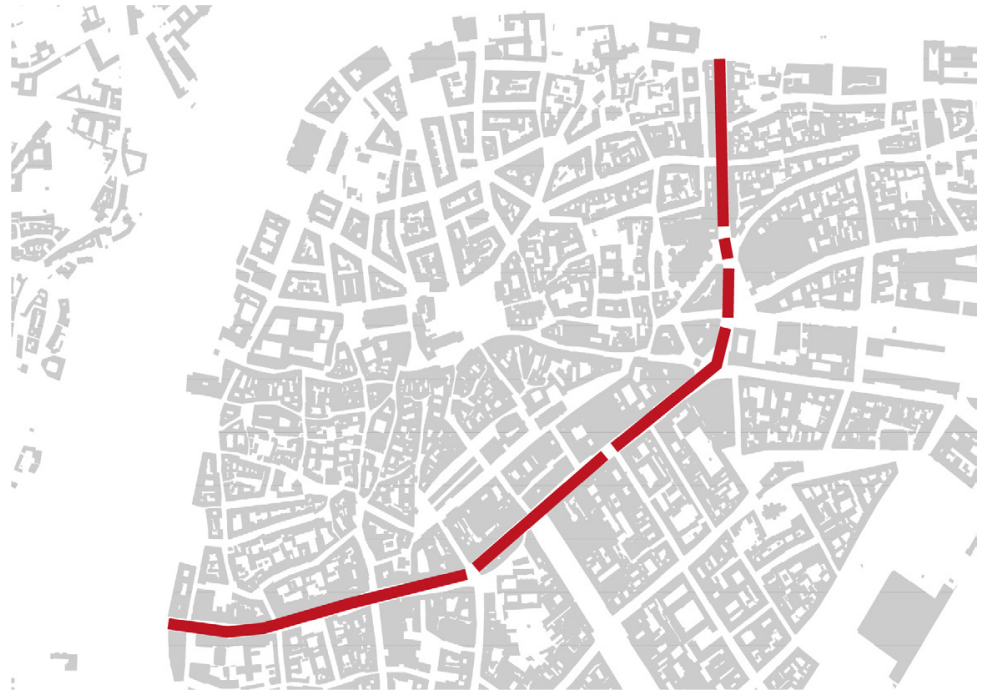

Fig. 3. Old Prague circuit - mixed-use street, fragmented into different traffic modes (Source: Author)

Mixed-use streets fulfill a wide range of place functions and, at the same time, it is a link for different modes of transport (Jones et al., 2007). Traditionally, central or local mixed-use streets have always been at the forefront of the requirements for residence and transport, which were in a close relationship and balance; transport mainly took place using slower and more sustainable modes (on foot, on horseback, by bike, and later on by tram), providing access and allowing other events to run freely. 

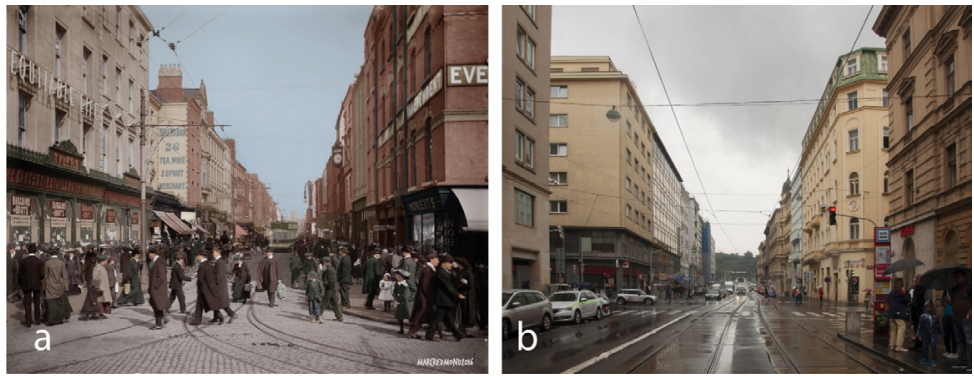

Fig. 4. a. Earl Street, Dublin, 1900 (Source: Pinterest); b. Revoluční, Prague, 2020 (Source: IPR, Prague)

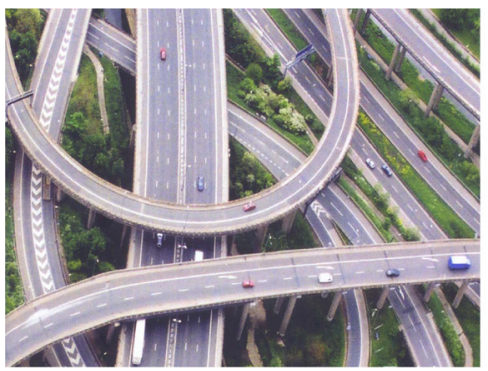

The Highway

- Regulated

- Impersonal

- Linear

- Single Purpose

- Consistent

- Predictable

- Systematic

- State controlled

- Signs and markings

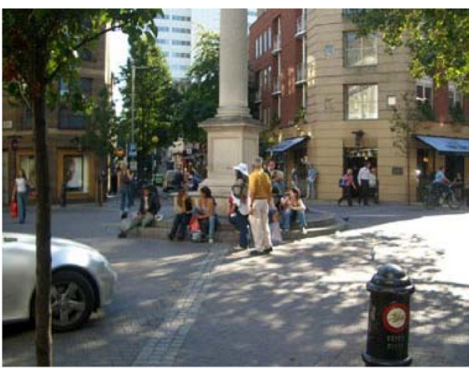

The Public Realm

- Culturally defined

- Personal

- Spatial

- Multi-purpose

- Constantly changing

- Unpredictable

- Contextual

- Cultural / social rules

- Multiple human communications

Fig. 5. The difference between Highway and public Place (Source: Hamilton-Baillie, 2005)

When the link or place function of such places is out of balance, people cannot freely move and use such places, so they avoid them, causing the loss of prosperity, the health of people, and the health of the entire city. An imbalance arises when car traffic and transport infrastructure dominate over other users and activities in the space. Imbalance could also occur when vehicles are completely excluded from the street. Since the development of mechanized transport and the subsequent development of the transport road hierarchy, both of which mainly addressed the issue of safety and efficiency of traffic, mixed-use streets are divided into two worlds - two demarcation space time. In the first case, pedestrian zones and highways exist separately in the 
structure of the city. In the other case, a vast variety of traffic calming engineering tools are used in order to combine them into one space of the street and to fulfill safety requirements. Nevertheless, the use of such engineering tools in such places anchors the dominance of highway character: regulated, predictable and single purpose, see Fig. 5.

But the place has absolutely opposite characteristics, so when these two different worlds of the highway and the public place try to connect, the most dangerous situation arises - chaos and ambiguity.
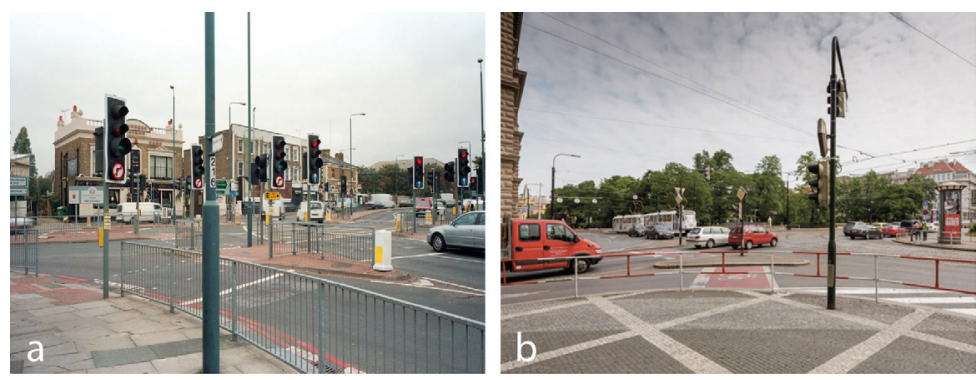

Fig. 6. a. Kew Bridge, London (Source: English Heritage); b. Charles' Square, Prague (Source: IPR, Prague)

Such processes still take place in the Czech Republic, thus showing that there is a great need to find another way of adapting driver behavior to other street users and activities.

\section{What is a shared space?}

Shared space is a traffic-calming urban design approach that integrates drivers into the street environment. The characteristic feature of the shared space theory is that the surroundings talk to its users, and it always has to tell the right story. Unlike the conventional calming measures or approaches (e.g., zone 30), which either physically or legislatively determine behavior through traffic signs and regulations, shared space uses the very context of the surrounding of public space, just as a restaurant, office or even ice rink evokes the certain behavior of its visitors (Hamilton-Baillie, 2008).

In this case, safety is ensured by the adaptation of behavior by the traffic participants them-selves - a process which is explained in more detail in the theory of risk com-pensation (Adams, 1985). 
In this case, safety is ensured by the adaptation of behavior by the traffic participants themselves - a process which is explained in more detail in the theory of risk compensation (Adams, 1985). The main goal is to achieve the equal use of public space for all users, which primarily means to achieve a considerate, respectful, conscious, and therefore safe type of behavior, where all elements that burden the public space and separate the driver from the events that take place around him are removed. These are traffic-engineering elements, such as legislative prohibitions, rules and protocols, signs, and markings, railings, traffic lights, curbs and speed bumps, which say to drivers:

"Go ahead, don't worry, go as fast as you want, there's no need to pay attention to your surroundings." ii

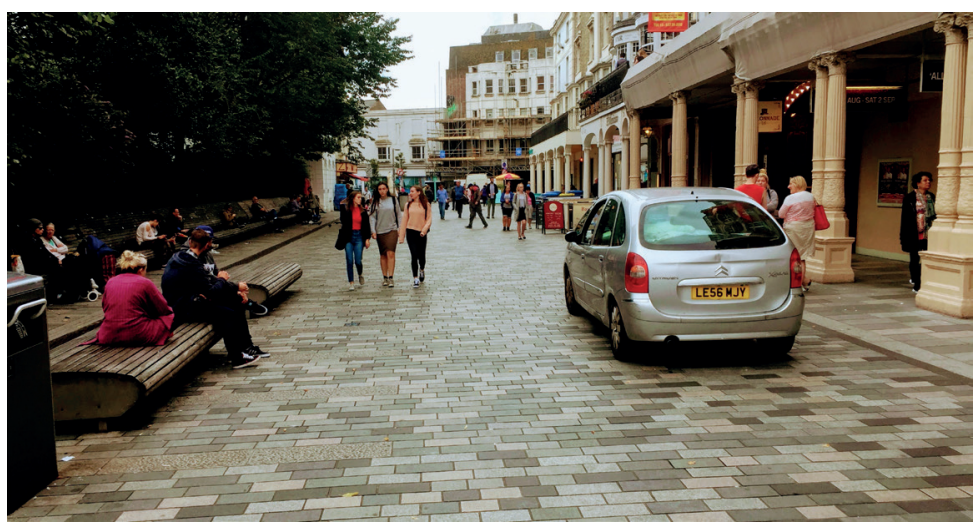

Fig. 7. New Road, Brighton (Source: PPS)

Shared space, basically, means the transfer of power and responsibility from the state to the individual and the community (PPS, 2008). The public space can be supplemented according to the needs of the specific location and by mutual agreement with better material design, urban furniture, public greenery, and other elements that form so-called 'edge friction'. It is necessary to realize that shared space is not a specific type of street, but it is an approach or a design process. Therefore, it can be represented by any form ${ }^{\mathrm{iii}}$ and a traffic sign. The achieved degree of the space sharing then depends on the individual elements, combinations thereof, and the location in the urban area ${ }^{\mathrm{iv}}$

The absence of traffic-engineering construction measures, that affect the dynamics of vehicles, in compliance with safe behavior and speed of road users involved in the public space, allows using a shared space approach not only on the local but also on the main roads. 


\begin{tabular}{|c|c|c|}
\hline Less shared design & & More shared design \\
\hline Kerbs & Low kerbs, chamfered kerbs & No kerbs \\
\hline Pedestrian barriers & & No pedestrian barriers \\
\hline $\begin{array}{l}\text { Vehicles restricted to parts of } \\
\text { street, e.g. by bollards, street } \\
\text { trees, etc. }\end{array}$ & $\begin{array}{l}\text { Implied vehicle paths using } \\
\text { surface materials, for example }\end{array}$ & $\begin{array}{l}\text { No barriers to vehicle } \\
\text { movement }\end{array}$ \\
\hline $\begin{array}{l}\text { Poor quality or unwelcoming } \\
\text { public space characteristics }\end{array}$ & $\begin{array}{l}\text { A few places where people } \\
\text { can rest and chat }\end{array}$ & $\begin{array}{l}\text { Presence of features such as } \\
\text { cafes, markets, abundant } \\
\text { seating, planting, public art, etc. }\end{array}$ \\
\hline Conventional road markings & Limited road markings & No road markings \\
\hline Traffic signals & & No traffic signals \\
\hline Signal controlled crossings & Zebra crossings & $\begin{array}{l}\text { Courtesy crossings or } \\
\text { no crossings }\end{array}$ \\
\hline
\end{tabular}

Fig. 8. Influence of typical features on sharing (Source: DfT, London)

\section{How does shared space help a mixed-use street?}

The shared space approach integrates drivers into their real surroundings by eliminating such burdensome reading space elements of transport infrastructure, and thus, forces the drivers to adapt their speed to the current situation. The streets tell a clear and understandable story.

All modes of transport give the same right of movement in all directions of public space, as required by the link and place function of mixed-use streets. In reality, the individual tried-and-tested implementations in different parts of the world (e.g., the Netherlands or the United Kingdom), show positive changes due to the application of the shared space approach to main roads with higher traffic intensities ${ }^{v}$.

All modes of transport give the same right of movement in all directions of public space, as required by the link and place function of mixed-use streets. In reality, the individual tried-and-tested implementations in different parts of the world (e.g., the Netherlands or the United Kingdom), show positive changes due to the application of the shared space approach to main roads with higher traffic intensities ${ }^{\mathrm{vi}}$.

\section{Conclusions}

Shared space is a potential approach to strengthening the quality of a place and increasing safety in mixed-use streets located in the Czech Republic. However, this is a theory that still needs to be tested. Although foreign practice shows positive results, respondents are sometimes dissatisfied with the ambiguous design of such places, and in some cases, they complain that drivers are unwilling to prioritize them. It is also not 
clear, which locations the shared space is acceptable for and what the extremes of traffic volumes are.

Can such spaces work together with railway public transport? How, and using which tools can shared space be verified, when the result of the design process depends on a wide number of various elements and combinations thereof, and when streets can thus take various forms? The question of the suitability of such an environment for blind, partially sighted and deaf people also remains open.
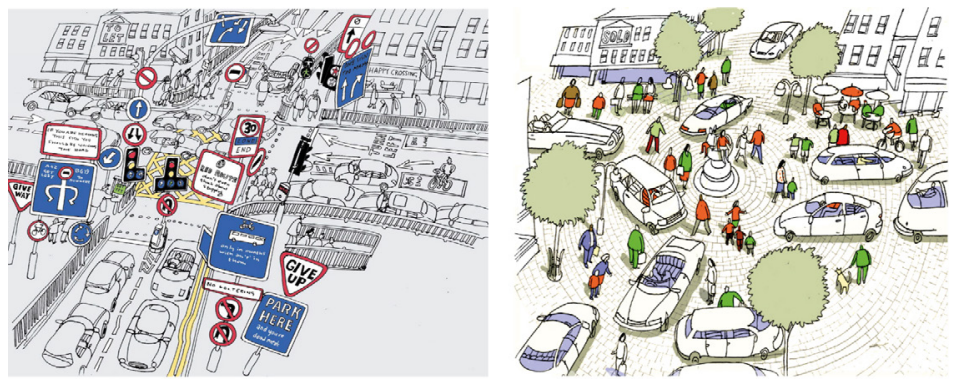

Fig. 9. The principle of shared space approach (Source: Hamilton-Baillie Associates)
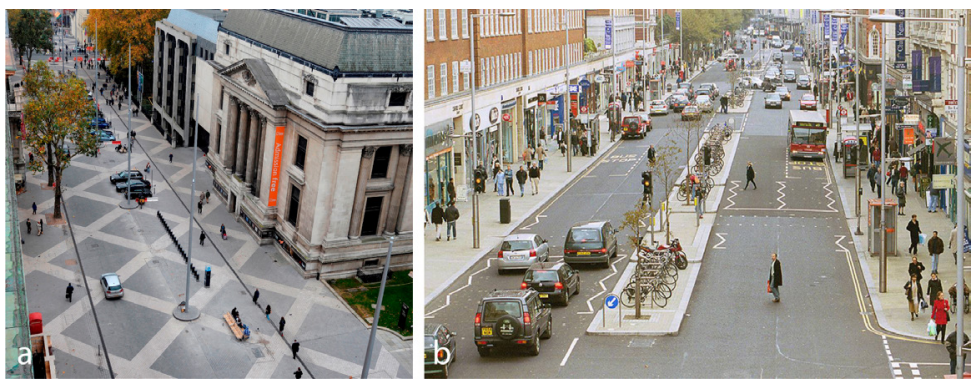

Fig. 10. a. Exhibition Road; b. Kensington High Street, West London (Source: RBKC)

\section{Sources}

ADAMS, J. G. D., 1985. Risk and freedom: The record of road safety regulation. 1. 59 Park Place, Cardiff CF1 3AT: Transport Publishing Projects. ISBN 0948537051. HAMILTON-BAILLIE, Ben, 2008. Shared space: Reconciling people, places and traffic [online]. UK: Scopus: Built Environment, 34(2), 161-181 [cit. 2017-08-24]. ISSN 0263-7960. 
JONES, Peter; ROBERTS, Marion; MORRIS, Linda, 2007. Rediscovering mixed use streets: the contribution of local high streets to sustainable communities. Policy Press in association with the Joseph Rowntree Foundation. ISBN 978186134 9859.

PPS, 2008. Hans Monderman. Placemaking heroes [online]. Dostupné z: https:// www.pps.org/article/hans-monderman

\section{Footnotes}

i CDV, 2010. Navrhování zón 30: technické podmínky: TP 218. str.7

ii PPS, 2008. Hans Monderman. Placemaking heroes [online]

iii CIHT, 2018. Creating Better Streets. Str. 10

iv DFT, 2011. Local transport note: Shared space (1/11). Str. 13

v CIHT, 2018. Creating Better Streets. Str. 27

iv CIHT, 2018. Creating Better Streets. Str. 27 